\title{
Participants' willingness to consume soy foods for lowering cholesterol and receive counselling on cardiovascular disease by nutrition professionals
}

\author{
Tamara Schryver and Chery Smith * \\ Department of Food Science \& Nutrition, University of Minnesota, 1334 Eckles Avenue, \\ St. Paul, MN 55108, USA
}

Submitted 18 May 2005: Accepted 21 November 2005

\begin{abstract}
Objectives: To determine if participants would be interested in consuming soy foods to lower cholesterol in primary and secondary prevention of heart disease, and to identify the role physicians and registered dietitians have in providing dietary advice, about soy foods or other foods, for participants with elevated cholesterol.

Methodology: Qualitative data from 12 focus groups were gathered from a convenience sample of 74 adults, aged 18-91 years, with and without high cholesterol (total cholesterol $>200 \mathrm{mg} \mathrm{dl}^{-1}$ ). Participants were recruited from Minneapolis/St. Paul mainstream and natural foods grocery stores. Focus group interviews were taped and transcribed verbatim. Common themes were identified, coded and compared using NVivo computer software.

Results: Participants believed diet, lifestyle and genetics were the cause of high cholesterol and cardiovascular disease (CVD). Few participants were aware of the Food and Drug Administration health claim for soy protein, yet many were willing to consume soy as part of lifestyle modification to prevent CVD. They reported preferring food and exercise over medication to treat high cholesterol. Few participants had ever received dietary advice from physicians on treating high cholesterol or CVD, and most doubted the accuracy of such advice. They believed registered dietitians were the most credible source of nutrition counselling and expressed an interest in physician referrals to dietitians.

Conclusions: A collaboration and referral system between physicians and registered dietitians could increase CVD patients' consumption of soy foods as a means potentially leading to a reduced risk of heart disease in participants.
\end{abstract}

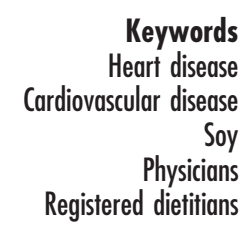

Cardiovascular disease (CVD) is the primary cause of death of men and women in the $\mathrm{USA}^{1}$, and is attributable to a combination of causes including genetic predisposition and a myriad of personal lifestyle choices ${ }^{2}$. Like most chronic diseases, these lifestyle choices can be modified to reduce risk of the disease or limit the damage done by the disease $e^{3-5}$.

Guidelines for the primary and secondary management of heart disease have been re-established by the National Cholesterol Education Program (NCEP) ${ }^{6}$. The Adult Treatment Panel III (ATP III) guidelines recommend maintaining lipid levels through the use of statins and other lipid medications ${ }^{7-10}$, thus increasing the number of drug-eligible patients from 15 to 36 million $^{8}$. Furthermore, ATP III introduced a lifestyle component, entitled Therapeutic Lifestyle Changes (TLC), which includes a diet similar to the previous NCEP II guidelines plus plant stanols/sterols and viscous fibre to lower low-density lipoprotein (LDL) cholesterol levels ${ }^{6}$. Soy protein is also included in the diet for cholesterol lowering ${ }^{6}$, consistent with the American Heart Association's dietary guidelines ${ }^{11}$ and a Food and Drug Administration (FDA)-approved soy protein health claim, which states: 'Diets low in saturated fat and cholesterol that include 25 grams of soy protein a day may reduce the risk of heart disease ${ }^{12}$. ATP III recommends concomitant diet therapy with medication use, as diet therapy provides additional cardiovascular benefits other than lipid reduction and may enhance drug effectiveness ${ }^{2,6}$.

The effectiveness of diet alone in lowering cholesterol levels has generally ranged from 4 to 13\%, compared with statins that lower LDL cholesterol by 18 to $55 \% \%^{3,13}$. Recently, a clinical trial comparing participants on a verylow-saturated-fat diet, a similar diet plus lovastatin or a 'portfolio' of cholesterol-lowering foods (plant sterols, soy protein, viscous fibre, almonds) found that the portfolio diet lowered LDL cholesterol similar to medication ${ }^{13}$. Margarines containing plant sterols, almonds and foods 
containing viscous fibre (primarily oats) are foods the typical American is familiar with.

However, Americans are fairly unfamiliar with soy ${ }^{14,15}$ and consume relatively few soy products ${ }^{16-19}$, with consumption being most common among vegetarians ${ }^{20}$, Asian Americans ${ }^{21,22}$, Seventh Day Adventists ${ }^{23}$ and a small portion of health-conscious consumers ${ }^{20,21}$. This limited acceptance of soy reduces its effectiveness as a therapeutic dietary treatment for lowering total and LDL cholesterol, whether within the context of a low-fat, lowsaturated-fat and low-cholesterol diet as suggested by the $25 \mathrm{~g}$ soy protein daily health claim ${ }^{12}$ or within the context of a combination diet such as the portfolio diet ${ }^{13}$.

The purpose of the present qualitative study was to determine whether people would be willing to consume soy foods as a method to lower cholesterol both in primary and secondary prevention, along with or in replacement of other dietary alternatives, lifestyle changes or medication use. For participants who choose not to consume soy, we sought to determine the preferred method for lowering cholesterol and to identify the barriers to soy consumption. Further, we wanted to verify whether non-consumers would increase their consumption of soy foods if informed of the health benefits. Finally, we wished to identify the role physicians and registered dietitians have in providing dietary advice, especially for patients with elevated cholesterol. This information could assist in designing future nutrition education interventions to stimulate increases in soy consumption potentially leading to a reduced risk of CVD in participants.

\section{Methods}

\section{Population and sampling}

Participants $(n=74)$, aged $18-91$ years, were recruited through fliers and newspaper ads from the urban and suburban community of Minneapolis/St. Paul to participate in focus groups. Focus group methodology provides the opportunity to obtain more in-depth information that is not available by quantitative research methods alone ${ }^{24}$ and has been used successfully to investigate adult perceptions of heart disease $\mathrm{e}^{25-29}$, although not of soy foods as treatment for CVD. We recruited people both with and without heart disease because we were interested in people's willingness to consume soy for both primary prevention and secondary care. The NCEP Step III recognises total cholesterol levels greater than $200 \mathrm{mg} \mathrm{dl}^{-1}$ as appropriate for follow-up ${ }^{3}$. We found participants were much more likely to know their total cholesterol rather than their LDL cholesterol level; therefore total cholesterol $>200 \mathrm{mg} \mathrm{dl}^{-1}$ was used as the cut-off for heart disease. Forty-two per cent of the participants self-reported having heart disease or high cholesterol. In this study, soy foods were soy food products and soy powders, but not soy isoflavone dietary supplements.

\section{Description of focus groups}

Twelve focus groups, containing a mix of participants who self-reported high cholesterol or normal cholesterol in the same groups, were conducted by the same two trained researchers ${ }^{24}$. Open-ended focus group questions were developed based on a review of the literature and pilottested prior to administration (Table 1). Responses from the pilot group were similar to responses from the main study groups and were therefore included in the analysis. Following each focus group, researchers met to debrief on the content discussed in order to clarify information or emerging themes. By the eleventh and twelfth focus groups, no new information on the topic of soy, heart

Table 1 Focus group questions for primary and secondary treatment of heart disease through soy consumption

1. Before you were diagnosed with high cholesterol, how did you make decisions on what types of foods to buy and eat?

Prompt: What factors drove you to choose one food over another in a grocery store?

Prompt: What factors drove you to choose one food over another in a restaurant?

Prompt: What factors drove you to choose one food over another at home?

2. Did nutritional value drive food behaviour? How?

Prompt: What is a healthy food?

Prompt: Can healthy foods taste good?

Prompt: Are there good foods and bad foods?

3. You have all been diagnosed with high cholesterol. What do you think is the cause of this condition?

Prompt: How do foods or diet contribute to or prevent high cholesterol?

Prompt: How does lifestyle contribute to high cholesterol?

Prompt: How does genetics or heredity contribute to high cholesterol?

4. What are your beliefs about soy foods?

Prompt: What's the first thing that comes to mind when you hear the word soy?

Prompt: Are soy foods healthy, and if so, why?

Prompt: What are some barriers to consuming soy?

Prompt: Where did you get your information about soy?

5. Have you ever tried soy foods?

Prompt: What kind?

Prompt: For how long?

Prompt: How many times each day do/did you eat soy?

Prompt: Why do/did you consume them?

6. Have you ever had a doctor, dietitian or nurse tell you to eat soy for health reasons?

Prompt: How much do doctors or nurses know about nutrition?

Prompt: Has a doctor ever referred you to a dietitian for nutrition counselling?

7. If you learned that soy could significantly lower your cholesterol, would you try to consume it on a regular basis?

Prompt: What barriers would have to be removed to consume it?

Prompt: Would lowering your cholesterol be worth the effort to learn about and consume soy?

8. How would you get people who don't consume soy on a regular basis to start doing so?

Prompt: Where could people learn about soy?

9. What is the best way for you to lower your cholesterol?

Prompt: How likely are you to change your diet to lower your cholesterol?

Prompt: How likely are you to start exercising to lower your cholesterol?

Prompt: How likely are you to start taking medication to lower your cholesterol? 
disease or treatment preferences was heard. This is the point of saturation, which represents an adequate sample size $^{24}$. At each session, which lasted approximately $90 \mathrm{~min}$, participants signed a consent form, completed questions regarding demographic information and received a monetary incentive. The study was approved by the University of Minnesota's Institutional Review Board for Research involving Human Subjects.

\section{Data analysis}

Demographic data were analysed using the Statistical Package for the Social Sciences for Windows (version 11; SPSS Inc., Chicago, IL, USA, 1999). Focus group discussions were audio-taped, transcribed verbatim and then imported into NUD*IST Vivo (NVivo) ${ }^{\circledR}$ software (QRS International Pty Ltd, Melbourne, Australia, 1999-2000) for coding. Coding of the transcripts was systematically conducted in a five-step process. First, researchers independently read each transcript to determine overall themes; second, they met to discuss and reconcile differences in identified themes prior to coding; third, one researcher coded the transcripts using NVivo while the other researcher manually coded transcripts; fourth, the coded transcripts were then compared again and reconciled; and fifth, re-occurring commonalities were identified in all 12 focus groups.

\section{Results}

The majority of the participants were female, white and had completed high school or some college (Table 2). Fifty-five per cent identified themselves as soy consumers, $23 \%$ as vegetarians/vegans and $42 \%$ as having heart disease or high cholesterol (Table 2). Of the 31 participants who had heart disease, 36\% reported consuming soy.

The major themes identified from the focus groups were: (1) causality of heart disease and high cholesterol; (2) willingness to consume soy to lower cholesterol; (3) preferred method for lowering cholesterol; and (4) physician and dietitian recommendations for lowering cholesterol.

\section{Causes of heart disease and bigh cholesterol}

Participants identified genetic predisposition and lifestyle choices as causes of heart disease and high cholesterol, regardless of their current health status or soy consumption status (Table 3).

\section{Genetic predisposition}

Participants believed that heart disease was inevitable for those with a family history. Some of the participants contested the extent to which genetics played a role in the acquisition of heart disease, stating that lifestyle exacerbates heredity.
Table 2 Socio-economic and lifestyle characteristics of focus group participants

\begin{tabular}{|c|c|}
\hline Characteristic & Number $(n=74)$ \\
\hline \multicolumn{2}{|l|}{ Gender } \\
\hline Male & 22 \\
\hline Female & 52 \\
\hline \multicolumn{2}{|l|}{ Age group (years) } \\
\hline $18-34$ & 22 \\
\hline $35-49$ & 16 \\
\hline $50-64$ & 22 \\
\hline$>65$ & 14 \\
\hline \multicolumn{2}{|l|}{ Race } \\
\hline White & 66 \\
\hline Black & 6 \\
\hline Hispanic & 1 \\
\hline Asian & 1 \\
\hline \multicolumn{2}{|l|}{ Education level } \\
\hline$<12$ th grade & 2 \\
\hline Completed high school & 7 \\
\hline Some college/technical/vocational school & 21 \\
\hline Completed college/technical/vocational school & 23 \\
\hline Completed graduate/professional school & 21 \\
\hline \multicolumn{2}{|l|}{ Income (\$US) } \\
\hline$<10000$ & 9 \\
\hline $10000-19999$ & 19 \\
\hline $20000-39999$ & 14 \\
\hline $40000-59999$ & 12 \\
\hline$>60000$ & 18 \\
\hline Unemployed & 2 \\
\hline \multicolumn{2}{|l|}{ Soy foods consumer } \\
\hline Yes & 41 \\
\hline No & 33 \\
\hline \multicolumn{2}{|l|}{ Vegetarian } \\
\hline Vegetarian or vegan & 17 \\
\hline \multicolumn{2}{|l|}{ Heart disease } \\
\hline Heart disease or high cholesterol & 31 \\
\hline
\end{tabular}

\section{Lifestyle}

Lifestyle was seen as moderating genetic predisposition toward heart disease. While diet and physical activity were viewed as major contributors to heart disease, other lifestyle factors identified included weight control, stress control, holistic health and wellness, moderation, balance, variety, environmental toxins, food commercialism and family culture.

\section{Diet}

Participants identified foods that could cause or prevent heart disease and high cholesterol. Foods reported as contributing to heart disease and high cholesterol included red meat, bacon, cheese, ice cream, salad dressing, eggs, cream, whole milk, salt, convenience foods and fast foods; whereas foods that prevented heart disease or were helpful for treating it included oats, fruits, vegetables, flax, fish, fish oil, garlic, red wine and whole foods (minimally processed foods). Foods that were high in sugar or starch were also believed to contribute to heart disease because of their influence on triglyceride and insulin levels. Soy foods were rarely mentioned as a means to decrease the risk of heart disease or cholesterol. A varied diet was viewed as more important than any one food. 
Table 3 Factors that contribute to or prevent heart disease and how to lower it

\begin{tabular}{ll}
\hline Cause & Representative quote \\
\hline
\end{tabular}

Diet

Animal products

Processed foods

Soy/portfolio diet

Soy foods

Soy foods

Oats

Fruits \& vegetables

Sugar

Starch

Saturated fat

Trans fat

Moderation/variety

Healthy diet

\section{Genetic predisposition}

Family history

\section{Lifestyle \\ Lifestyle}

Physical activity/diet

Diet

Diet

Lifestyle

Medication

Medication

Medication plus diet

Willing to consume soy

Need barriers removed

Not willing to consume soy Education
'I think it's the heavy consumption of milk and dairy products and meat.'

'So I think as long as you're eating mostly whole foods as opposed to things that come in boxes and packages ... in all likelihood you're probably doing a pretty good job keeping your body in shape.'

'I heard soy and almonds, and just the whole ... portfolio diet ... I tried to incorporate that and it actually did go down?

'Well my mother had a triple by-pass about five years ago, and she has a pace maker right now. And I introduced her to soymilk, and she enjoyed it. She started drinking it. And I think that's helped lengthen her life. Because the doctor had given her just one year to live, and it's been five since she had it. So I think the soymilk has really helped to sustain her and keep her in reasonable amount of health.'

'When they diagnosed me, I cut out some things completely from my diet, and I did seek out soy products, and rice products. And I did not like the taste in a lot of cases.' (barrier to consumption) 'High cholesterol will make me choose something like oatmeal for breakfast.'

'With fruits and vegetables there's lots of studies that high consumption can lower cholesterol.'

'I was eating a lot of sugar in other forms ... and that gets converted into triglyceride fat, which is just as bad.'

'I used to eat ... baked potatoes almost every day and now l've switched to sweet potatoes and yams. I think it has a different effect on your body than potatoes because it turns into something, it gets your insulin to work, or something works harder. You might be more prone to diabetes or something like that. It all seems to be tied together, the diabetes, the cholesterol, all of it.'

'If you eat a lot of meat then that's a lot of saturated type fat, and that clogs up those vessels and arteries. So that's not real good.'

'Three Oreo cookies has the same amount of saturated fat as four strips of bacon. But it's all the trans fat, which is like super bad.'

'A healthy diet would be whole foods, fruits, vegetables, grains, and ... natural meats ... organic meats in moderation... If a person really kept to that diet, that would take care of heart disease ... and lessen serious risks.'

'I wasn't thinking about my cholesterol. That's not something I normally think about when I'm eating, whether I'm going to a grocery store or eating in a restaurant. I hardly ever think about my cholesterol at all. I just have fairly healthy eating habits.

'I know my parents' parents all died of heart attacks and stroke and their parents and grandparents, and everyone as far back as anyone can remember, even when it was a time before they diagnosed it. It was like they found so-and-so out in the field. Well it was pretty obvious he had a heart attack out there ... so it's definitely in the family ... and if I count everything [diet and lifestyle], I would still have it.'

'I really believe in lifestyle exacerbating genetic predisposition. And that the things that you can choose to live your life, like exercise, and diet, and everything, can definitely impact what you may genetically be predisposed to.'

'I think ... sedentary, McDonald's eating, sitting-at-the-cube lifestyle.'

'I have great faith in food as healing.'

'Do I want to spend the rest of my life not eating what I want to? What kind of life is that? I've given up this, this, this, ha! Give me a break! That's how I feel. I mean I know better. I don't want to be the purpose, the fault of my own death, but then again, not eating the stuff I like?

'I would always go try to modify the behavior first ... and lower it first naturally.'

'I've been trying to work on [diet and exercise] for a while, and I guess I've had minimal success. My cholesterol hasn't really gone down... If I had to go on drugs ... that would be OK.'

'They give you that little print out of all the drugs ... and the side-effects, and I go, "Oh! If the disease isn't going to kill you, the drugs will!".'

'I was kind of given the sense now that I had the pill it really didn't make any difference what I ate. That was until I had my double bypass.'

'I think that [soy] would be a preferred option to any medication. So if it came down to a choice like that, maybe it would be biased to start with because I think anything that's natural is better than some kind of something from a pharmaceutical company.'

'If I was in the heart disease situation I think I would be more willing to switch if the doctor or whoever either provided a recipe or diet plan, or some kind of way to actually use it [soy].'

'I didn't eat any fat, I ate the soy. But ten! Ten! It wasn't worth just lowering it ten points.'

"I thought the best way to lower cholesterol is to get knowledgeable about what may help to lower cholesterol ... I think finding what you like to do, that will help you get to where you want to be.'
The nutrients drawing the most attention by participants concerned with heart disease were fat, saturated fat, trans fat and fibre. Participants demonstrated a basic understanding of the different types of fats, although terminology was commonly confused in discussion.
Participants were also confused as to whether it was better to choose low- or no-fat foods for heart disease compared with foods with poly- or monounsaturated fats, and were equally perplexed as to whether to consume margarine over butter, canola oil or olive oil. Few 
understood the relationship between hydrogenation and trans fatty acids, or understood food sources of each type of fat. In spite of the confusion, a few participants reported switching their butter or margarine spread to a specialty margarine such as Smart Balance or the stanol/sterol margarines. A few participants believed soy foods were harmful for heart disease because some contain fat.

\section{Willingness to consume soy to lower cholesterol}

When researchers asked participants if they knew of the FDA soy health claim, very few were familiar with it although many reported regularly reading the nutrition label on food packaging. Some participants had noticed the 'heart healthy' logo on soy packaging but doubted the truthfulness of the claim. There was a general understanding that soy foods were a good substitute for animal protein and, as such, lower in saturated fat and beneficial for those with heart disease. The majority of participants were willing to consume soy foods to help lower their cholesterol if they had high cholesterol because they believed foods offered a better alternative to medication.

However, some participants objected to consuming more soy foods for lowering of cholesterol for a variety of reasons or thought that barriers needed to be removed before seriously considering it a realistic option. Overcoming a negative perception of soy's taste and understanding how to incorporate it into a diet or prepare it appeared to be the greatest problems to its acceptance. A few participants objected to the number of servings of soy required by the health claim, which is four per day. Participants believed they could likely fit one serving of soy foods into their daily diet, but not four per day.

Focus group participants were able to assist each other in troubleshooting practical barriers to soy consumption; however, a few people objected to consuming soy foods because of philosophical reasons or concerns over the safety of soy foods. Two participants had actually incorporated soy to lower their cholesterol, and while one was successful in doing so, the other felt the effort wasn't worth the reduction in cholesterol.

\section{Preferred method for lowering cholesterol}

There was a good deal of discussion regarding participants' cholesterol levels, fluctuations, medical advice and ways to lower it, including participants' personal experience with diet and lifestyle modification and medication use (Table 3). The most commonly expressed opinion regarding lowering cholesterol was to use any method that focused on dietary and lifestyle change first. Participants cited increasing consumption of fruits, vegetables and fibre, decreasing consumption of red meat, switching to low-fat dairy alternatives, and experimenting with soy foods.

While participants agreed diet modification was the preferred method for lowering cholesterol, many with heart disease or high cholesterol did not believe diet alone would work. Some believed they had no control over their genetic background. Several participants with borderline high cholesterol levels reported not feeling at immediate risk for a heart attack, while others voiced frustration with having to modify their diet and questioned whether it was worth it. Others had given up attempting to change their lifestyle and suggested that their higher levels of cholesterol were considered normal. Finally, a few of the participants who had had limited success in lowering their cholesterol through diet modification were contemplating medication as the next step.

Using medication to control heart disease was widely viewed as efficacious but undesirable; although for some, necessary. Many were concerned with medication sideeffects and prescription costs. Some participants reported relaxing their dietary changes while using medications.

A handful of participants expressed a preferred interest in using dietary supplements to treat heart disease as they were seen as more natural alternatives to medication. The most commonly mentioned over-the-counter supplement was niacin. Several participants mentioned educating themselves first as to the best way to lower their cholesterol, and then embarking on a method. Finally, one participant had already decided on gastric bypass surgery over lifestyle modification to help her lower her weight and severity of CVD.

\section{Physician and dietitian recommendations for lowering cholesterol}

Participants obtained their health-related information from family, friends, books, magazines, media, food labels, the scientific community and health-care professionals. Because physicians were the most commonly cited source of dietary information in terms of health-care professionals, we specifically asked participants about their encounters with registered dietitians, their willingness to be counselled by registered dietitians and their perspective on physicians' willingness to refer them to registered dietitians (Table 4). Although there was a heavy reliance on physician advice, many participants were sceptical about the nutrition knowledge of physicians and whether or not physicians would prescribe dietary advice over medication. Some participants were dubious of physician advice given the recent trend for doctors to recommend the Atkin's diet. Many believed that physicians did not receive adequate nutrition training in school and that they were not qualified to provide nutrition education counselling. Others felt confident their physician had good intentions for treating them, but didn't always have the time or the most current information to provide personalised nutrition counselling.

Some physicians provided nutrition counselling to patients with high cholesterol, but the majority did not, nor did they provide referrals to a registered dietitian. A few participants reported receiving brochures from their physician on how to lower cholesterol, but noted the lack of personalisation. Other participants reported their 
Table 4 Physician and registered dietitian recommendations for lowering cholesterol

\begin{tabular}{|c|c|}
\hline Practitioner & Representative quote \\
\hline \multicolumn{2}{|l|}{ Physician } \\
\hline Lack of training & $\begin{array}{l}\text { 'I... was shocked ... to find out that medical doctors were not required to take any nutrition courses!... This } \\
\text { blew me out of the sky thinking you're going to doctors thinking they know what it's all about, and somewhere } \\
\text { in my own mind I always associated nutrition with health.' }\end{array}$ \\
\hline Lack of training & $\begin{array}{l}\text { 'I have typically ignored what doctors have said about nutrition... I don't think they've had any kind of training or } \\
\text { knew anything about it. I've heard them say things that are really just wrong. I think they are getting to a point } \\
\text { now where they are beginning to look at nutrition as really important. I think there's some change, but } \\
\text { typically I don't pay much attention to them.' }\end{array}$ \\
\hline Lack of training & $\begin{array}{l}\text { 'The medical community [physicians] is not the people to go to for nutrition. But they're real good about handing } \\
\text { out pills and stuff.' }\end{array}$ \\
\hline Lack of time & $\begin{array}{l}\text { 'I also distrust the amount of time my doctor has to actually look at the test results and actually sit down and } \\
\text { talk to me. I don't distrust my doctor's knowledge base or that they could give good advice. I just distrust the } \\
\text { fact that I'm in that room for ten minutes and there is no way she can hear everything I'm telling her.' }\end{array}$ \\
\hline Use of brochures & $\begin{array}{l}\text { 'They usually just send something [brochures] home on how to lower your cholesterol. It's nothing. It's the same } \\
\text { stuff every time you go so I think it's just something they hand out to everybody.' }\end{array}$ \\
\hline Use of brochures & $\begin{array}{l}\text { 'My doctor called me up and said you're at } 217 . . \text { It's not life threatening or anything, but you need to cut back } \\
\text { on the fats in your diet. And then ... the clinic sent me something in the mail with diet guidelines.' }\end{array}$ \\
\hline Endorsement of soy & $\begin{array}{l}\text { 'If he were to say, "Well, you can take some statins or you can do this [soy]", I would be much more inclined to } \\
\text { bite the bullet and start chewing on soy nuts.' }\end{array}$ \\
\hline \multicolumn{2}{|l|}{ Registered dietitians } \\
\hline Reliable source & $\begin{array}{l}\text { 'I think doctors have very little education concerning food and nutrition. If you want to get the facts, see } \\
\text { somebody that is a dietitian.' }\end{array}$ \\
\hline Need for referral & $\begin{array}{l}\text { 'I think a lot of times physicians don't see the point of referring someone like you to a dietitian because they } \\
\text { don't think it's worthy.' }\end{array}$ \\
\hline Expense & $\begin{array}{l}\text { 'It would be an out-of-pocket expense, where I think a lot of people would rather try it on their own because the } \\
\text { information is out there for them to read.' }\end{array}$ \\
\hline Beneficial & $\begin{array}{l}\text { 'I never took any kind of medication and I totally lowered mine [cholesterol] ... because I went to a nutritionist } \\
\text { and got a bunch of ideas and I was really strict with myself.' }\end{array}$ \\
\hline Access to medication & $\begin{array}{l}\text { 'I had to take a class when I had high cholesterol before I got on medication ... and it was [taught by a } \\
\text { dietitian]. That was one of their requirements to get on it. I mean, you can't go walking through their door, I } \\
\text { don't think, and lower your cholesterol with a drug.' }\end{array}$ \\
\hline
\end{tabular}

doctor provided dietary counselling when their cholesterol was borderline high.

Participants were willing to visit with a nutrition professional for dietary counselling but wanted a referral from their physician as they were concerned about having to pay for the visit on their own. A small number of participants had seen a registered dietitian, through doctor referrals or on their own, and felt the counselling was worthwhile in that it provided them with credible information, knowledge on how to compose a cholesterol-lowering diet and basic survival tips. A few, who had been successful in lowering their cholesterol through diet, partially attributed the success to their visit with a registered dietitian. One participant was sent to see a registered dietitian by his physician before statin use was considered.

In our study, only one physician recommended soy foods for lowering cholesterol. Of the few participants who had seen a registered dietitian, none of them said the registered dietitian recommended soy. Despite this, participants said they would try soy foods to lower their cholesterol if their doctor recommended it, but preferred to get the information from a registered dietitian.

\section{Discussion}

The major findings in our study were identification of participant beliefs on the causes of heart disease and high cholesterol, participant willingness to consume soy foods to lower cholesterol, a preference for foods over medication to lower cholesterol, and the role patients perceived that physicians and dietitians had in providing nutrition advice about heart disease or high cholesterol. Participants expressed a preference for incorporating dietary changes that focused on several foods, rather than targeting one food, and exercise as ways to prevent and treat heart disease. There was little recognition of the soy protein heart health claim in spite of the fact that $55 \%$ of all participants and 36\% of participants with heart disease described themselves as soy consumers. Once informed of the soy protein health claim, participants were willing to incorporate soy into their diet for lowering cholesterol.

The preference for overall diet and lifestyle change in treating CVD is supported by previous research literature $e^{6,30,31}$; however, our participants expressed difficulty in modifying their lifestyle. Earlier qualitative research revealed that participants who did not have heart disease or stroke believed dietary recommendations for CVD prevention did not pertain to them because they had not yet been diagnosed with the disease ${ }^{32}$. Participants in our study not diagnosed with CVD similarly underestimated their risk of disease with only a few reporting adherence to a heart-healthy diet; although in contrast to Krueger and Casey's study ${ }^{32}$, our participants believed everyone should follow a healthy diet that could also help prevent heart 
disease. Other studies have also reported the tendency for non-diagnosed persons to underestimate their risk of $\mathrm{CVD}^{27,33,34}$, unless there is an awareness of a prior family history $^{35}$. Likewise, we found that awareness of one's genetic predisposition to heart disease appeared to motivate some people to engage in dietary and lifestyle modification, while discouraging those with more fatalistic views. We also observed an improved adherence to diet or lifestyle modification among those actually diagnosed with CVD. Earlier research on diet and lifestyle habits of people has shown that those diagnosed with hypercholesterolaemia are more likely to attempt improved dietary and exercise habits than those not diagnosed ${ }^{36,37}$. Our participants were also uninterested in primary heart disease prevention, but willing to participate in secondary prevention. More research is needed to identify the characteristics of people who have the ability and selfefficacy to adhere to a healthy diet for primary prevention.

In the present study, participants identified fat as the main dietary contributor to heart disease. This is similar to the findings of previous research on consumer perspectives on the causes of heart disease ${ }^{38,39}$. Further, participants were aware of the role of trans fatty acids in heart disease, although at times they had difficulty in identifying food sources of trans fats and were unable to compare its detrimental effects on health with those of saturated fat. Similar confusion with the different types of fats has been found in other studies ${ }^{40-42}$. The International Food Information Council Foundation has documented an increased consumer awareness of trans fatty acids in food labelling ${ }^{43}$. Likewise, many of the participants in our group who were actively pursuing a heart-healthy diet reported an increase in searching food labels for trans fatty acid information.

Participants in our study were most likely to choose fruits, vegetables and oats or fibre to prevent heart disease, with very few suggesting soy foods as a method for lowering the risk of CVD without researcher prompting. Barriers to soy consumption appeared to be related to soy's negative image, a lack of familiarity on how to prepare soy foods, and a perception that soy foods were an inadequate flavour substitute for animal-based products $^{14}$. Nevertheless, the majority of our participants were willing to consume soy to help prevent CVD or lower their cholesterol once they were informed of the FDA health claim. This is similar to research conducted with cardiac rehabilitation patients' willingness to consume functional foods ${ }^{44}$. When presented with information on soy foods, $97 \%$ reported an intention to increase soy consumption ${ }^{44}$.

Problems with patient adherence to dietary, lifestyle or medication regimens to lower cholesterol have been well reported $^{45-47}$, but our patients' preference for dietary and lifestyle modification over medication remains fairly novel. Although medication use is justified in patients with coronary heart disease (CHD) or CHD risk equivalents and in patients with high levels of 10-year risk and high LDL cholesterol levels, a significant number of people should engage in NCEP's Step III TLC first ${ }^{3,7,48,49}$. Most participants in our study agreed they would rather try diet and lifestyle modification before medication because of concerns associated with the cost, side-effects and longterm effects of lifelong medication use. However, because of a lack of knowledge about an appropriate CVD diet and the difficulty in adhering to dietary change, participants expressed an interest in personalised counselling with a registered dietitian. This would also be beneficial for participants who reported abandoning a prudent diet when prescribed medications.

Participants reported a variety of CVD-related experiences with physicians, with a few physicians aggressively treating high cholesterol with diet and medication advice, some using medications, and others providing little or no treatment for those with borderline high cholesterol. The variety of experiences is most likely attributable to the recent change in NCEP guidelines as well as participant recall. Nevertheless, other research has noted variance in physician treatment for primary and secondary CVD, with dietary advice equally subject to fluctuation ${ }^{36,47,50-55}$. This fluctuation in treatment may contribute to why only $38 \%$ of all patients reach treatment goals ${ }^{47}$.

Physicians are no doubt overwhelmed with administering the TLC portion of NCEP III guidelines. Although some participants with high cholesterol received dietary advice from physicians, the majority did not. Further, our participants recognised the limited nutrition education of physicians and expressed a desire for physician referral to nutrition professionals. Earlier research has shown that two-thirds of physicians provide five or fewer minutes in nutrition counselling to $40 \%$ of their patients or less 55 . Most physicians understand the barriers in delivering nutrition counselling and agree they should utilise the services of a registered dietitian ${ }^{55}$, yet only half of nutrition counselling is provided by registered dietitians ${ }^{55}$. It is important to identify why physicians are not referring patients with heart disease to nutrition professionals for counselling. The two professionals, working together, could be more successful in helping patients manage their condition, especially considering that registered dietitians have delivered successful medical nutrition therapy for lowering cholesterol in the past ${ }^{56-58}$.

Seventeen per cent of our sample was vegetarian, $41 \%$ were soy consumers and $31 \%$ had heart disease or high cholesterol. These percentages are higher than the national estimates of $6-10 \%{ }^{59}, 25 \%{ }^{42}$ and $17 \%{ }^{60}$, respectively, which means our sample was not representative of the typical American population. However, we purposefully recruited participants from a variety of locations, including natural foods stores, in an effort to have equal numbers of soy consumers and nonconsumers with and without heart disease and high cholesterol for content comparison purposes. This resulted in rich and diverse content. 


\section{Conclusion}

Research on the efficacy of soy foods for lowering cholesterol, whether part of the NCEP III diet or as part of a portfolio of CVD-beneficial foods, warrants its use and recommendation in both primary and secondary prevention of CVD. However, participants' limited understanding of the health benefits of soy foods and how to incorporate it into the overall diet inhibit its usefulness. Participants expressed a willingness to consume soy, but need information on how to use it. While physicians are important in validating the credibility of soy foods, registered dietitians can help patients overcome barriers to incorporating soy foods into their diet provided better referral mechanisms are set up between the physician and dietitian. Finally, recommending soy foods as part of the TLC diet in conjunction with statin use could potentially maximise any cholesterol-lowering attempts.

\section{Acknowledgements}

We would like to thank Mississippi Market, St. Paul, MN, and Roundy's, Inc./Rainbow Food grocery stores, Minneapolis/St. Paul, MN, for allowing us to conduct focus groups in their stores. We thank all participants for generously agreeing to participate in our study.

\section{References}

1 American Heart Association (AHA). Heart Disease and Stroke Statistics - 2004 Update. Dallas, TX: AHA, 2004. Also available at http://www.americanheart.org/presenter. jhtml?identifier $=3000090$. Accessed 29 June 2004.

2 Schaefer EJ. Lipoproteins, nutrition, and heart disease. American Journal of Clinical Nutrition 2002; 75: 191-212.

3 Expert Panel on Detection, Evaluation, and Treatment of High Blood Cholesterol in Adults. Executive summary of the Third Report of the National Cholesterol Education Program (NCEP) Expert Panel on detection, evaluation, and treatment of high blood cholesterol in adults (Adult Treatment Panel III). Journal of the American Medical Association 2001; 285: 2486-97.

4 Hu FB, Willett WC. Optimal diets for prevention of coronary heart disease. Journal of the American Medical Association 2002; 288: 2569-78.

5 Ornish D, Scherwitz LW, Billings JH, Brown SE, Gould KL, Merritt TA, et al. Intensive lifestyle changes for reversal of coronary heart disease. Journal of the American Medical Association 1998; 280: 2001-7.

6 National Cholesterol Education Program Expert Panel on Detection, Evaluation, and Treatment of High Blood Cholesterol in Adults (Adult Treatment Panel III). Third Report of the National Cholesterol Education Program (NCEP) Expert Panel on Detection, Evaluation, and Treatment of High Blood Cholesterol in Adults (Adult Treatment Panel III): Final Report. NIH Publication No. 025215. Washington, DC: National Cholesterol Education Program, National Heart, Lung, and Blood Institute, National Institutes of Health, 2002.

7 Eidelman RS, Lamas GA. The new National Cholesterol Education Program guidelines: clinical challenges for more widespread therapy of lipids to treat and prevent coronary heart disease. Archives of Internal Medicine 2002; 162: 2033-6.

8 McKenney JM. New cholesterol guidelines, new treatment challenges. Pharmacotherapy 2002; 22: 853-63.

9 Davidson MH. Strategies to improve Adult Treatment Panel III guidelines adherence and patient compliance. American Journal of Cardiology 2002; 89: 8C-22C.

10 Grundy SM, Cleeman JI, Bairey Merz CN, Brewer HB Jr, Hunninghake D, Posternack RC. Implications of recent clinical trials for the National Cholesterol Education Program Adult Treatment Panel III guidelines. Circulation 2004; 110: 227-39.

11 Krauss RM, Eckel RH, Howard B, Appel LJ, Daniels SR, Deckelbaum RJ, et al. AHA Dietary Guidelines Revision 2000: a statement for healthcare professionals from the Nutrition Committee of the American Heart Association. Circulation 2000; 102: 2284-99.

12 Food and Drug Administration. Food Labeling: Health Claims; Soy Protein and Coronary Heart Disease. Washington, DC: US Department of Health and Human Services, 26 October 1999; (64)(206): 57699-7733 [21 CFR Part 101].

13 Jenkins DJA, Kendall CWC, Marchie A, Faulkner DA, Wong JM, de Souza R, et al. Effects of a dietary portfolio of cholesterol-lowering foods vs lovastatin on serum lipids and C-reactive protein. Journal of the American Medical Association 2003; 290: 502-10.

14 Schryver T, Smith C. Reported attitudes and beliefs toward soy food consumption of soy consumers versus non-consumers in natural foods or mainstream grocery stores. Journal of Nutrition Education and Behavior 2005; 37: 292-9.

15 Wenrich TR, Cason KL. Consumptions and perceptions of soy among low-income adults. Journal of Nutrition Education and Behavior 2004; 36: 140-5.

16 Horn-Ross PL, Lee M, John EM, Koo J. Sources of phytoestrogen exposure among non-Asian women in California, USA. Cancer Causes \& Control 2000; 11: 299-302.

17 Lampe JW, Gustafson DR, Hutchins AM, Martini MC, Li S, Wahala $\mathrm{K}$, et al. Urinary isoflavonoid and lignan excretion on a Western diet: relation to soy, vegetable, and fruit intake. Cancer Epidemiology, Biomarkers \& Prevention 1999; 8: 699-707.

18 de Kleijn MJJ, van der Schouw YT, Wilson PWF, Adlercreutz H, Mazur W, Grobbee DE, et al. Intake of dietary phytoestrogens is low in postmenopausal women in the United States: the Framingham study. Journal of Nutrition 2001; 131: 1826-32.

19 Goodman-Gruen D, Kritz-Silverstein D. Dietary isoflavone intake is associated with cardiovascular disease risk factors in postmenopausal women. Journal of Nutrition 2001; 131: $1202-6$.

20 Gilbert L. 2001 HealthFocus ${ }^{\circledR}$ Fast Facts Report: Soyfoods Shoppers 2001: Who They Are, Why They Buy. Atlanta, GA: HealthFocus, Inc., 2001.

21 Rice MM, LaCroix AZ, Lampe JW, van Belle G, Kestin M, Sumitani M, et al. Dietary soy isoflavone intake in older Japanese American women. Public Health Nutrition 2001; 4: 943-52.

22 Maskarinec G, Singh S, Meng L, Franke AA. Dietary soy intake and urinary isoflavone excretion among women from a multiethnic population. Cancer Epidemiology, Biomarkers \& Prevention 1998; 7: 613-9.

23 Resnicow K, Barone J, Engle A, Miller S, Haley N, Fleming DWE. Diet and serum lipids in vegan vegetarians: a model for risk reduction. Journal of the American Dietetic Association 1991; 91: 447-53.

24 Morgan DL, Krueger RA. The Focus Group Kit. Volumes 1-6. Thousand Oakes, CA: Sage, 1997. 
25 Lisk CJ, Grau L. Perceptions of women living with coronary heart disease: an overview of study findings. American Journal of Geriatric Cardiology 1999; 8: 157-61.

26 Gettleman L, Winkleby MA. Using focus groups to develop a heart disease prevention program for ethnically diverse, low-income women. Journal of Community Health 2000; 25: 439-53.

27 Krummel DA, Humphries D, Tessaro I. Focus groups on cardiovascular health in rural women: implications for practice. Journal of Nutrition Education and Behavior 2002; 34: 38-46.

28 Covello VT, Peters RG. Women's perceptions of the risks of age-related diseases, including breast cancer: reports from a 3-year research study. Health Communication 2002; 14 377-95.

29 Nic Gabhainn S, Kelleher CC, Naughton AM, Carter F, Flanagan M, McGrath MJ. Socio-demographic variations in perspectives on cardiovascular disease and associated risk factors. Health Education Research 1999; 14: 619-28.

30 Dietary Guidelines Advisory Committee. The Report of the Dietary Guidelines Advisory Committee on the Dietary Guidelines for Americans [online], 2000. Available at http:// www.health.gov/dietaryguidelines/dgac. Accessed 22 July 2004

31 US Department of Health and Human Services. A Public Health Action Plan to Prevent Heart Disease and Stroke: Executive Summary and Overview. Atlanta, GA: US Department of Health and Human Services, Centers for Disease Control and Prevention, 2003.

32 Krueger R, Casey MA. Preventing Heart Disease and Stroke: Summary of Focus Groups with People Living in Minnesota. St. Paul, MN: Krueger \& Associates, 2002.

33 Green JS, Grant M, Hill KL, Brizzolara J, Belmont B. Heart disease risk perception in college men and women. Journal of the American College of Health 2003; 51: 207-11.

34 Shepherd R. Social determinants of food choice. Proceedings of the Nutrition Society 1999; 58: 807-12.

35 Montgomery GH, Erblich J, DiLorenzo T, Bovbjerg DH. Family and friends with disease: their impact on perceived risk. Preventive Medicine 2003; 37: 242-9.

36 Thomas RJ, Kottke TE, Brekke MJ, Brekke LN, Brandel CL, Aase LA, et al. Attempts at changing dietary and exercise habits to reduce risk of cardiovascular disease: who's doing what in the community? Preventive Cardiology 2002; 5: 102-8.

37 Aubin M, Godin G, Vezina L, Maziade J, Desharnias R. Hypercholesterolemia screening. Does knowledge of blood cholesterol level affect dietary fat intake? Canadian Family Physician 1998; 44: 1289-97.

38 Karner A. Coronary heart disease: causes and drug treatment-spouses' conceptions. Journal of Clinical Nursing 2004; 13: 167-76.

39 Troein M, Rastam L, Selander S, Widlund M, Uden G. Understanding the unperceivable: ideas about cholesterol expressed by middle-aged men with recently discovered hypercholesterolaemia. Family Practitioner 1997; 14: 376-81.

40 Borra S, Kelly L, Tuttle M, Neville K. Developing actionable dietary guidance messages: dietary fat as a case study. Journal of the American Dietetic Association 2001; 101 678-84.

41 Karner A, Goransson A, Bergdahl B. Conceptions on treatment and lifestyle in patients with coronary heart disease - a phenomenographic analysis. Patient Education and Counseling 2002; 47: 137-43.

42 United Soybean Board. National Report 2004-2005. Consumer Attitudes about Nutrition. Insights into Nutrition, Healthy and Soyfoods. St. Louis, MO: United Soybean Board, 2004. Also available at http://www.talksoy.com/pdfs/ ConsumerAttitudes2004.pdf. Accessed 9 August 2004.

43 International Food Information Council Foundation (IFIC), Cogent Research. Impact of Trans Fat Label Information on
Consumer Food Choices. Washington, DC: IFIC, 2003. Also available at http://www.ific.org/research/transres.cfm. Accessed 21 July 2004.

44 Pelletier S, Kundrat S, Hasler CM. Effects of a functional foods nutrition education program with cardiac rehabilitation patients. Journal of Cardiopulmonary Rehabilitation 2003; 23: 334-40.

45 Lappalainen R, Koikkalainen M, Julkunen J, Saarinen T, Mykkanen H. Association of demographic factors with barriers reported by patients receiving nutrition counseling as part of cardiac rehabilitation. Journal of the American Dietetic Association 1998; 98: 1026-9.

46 Stilley CS, Sereika S, Muldoon MF, Ryan CM, Dunbar-Jacob J. Psychological and cognitive function: predictors of adherence with cholesterol lowering treatment. Annals of Behavioral Medicine 2004; 27: 117-24.

47 Pearson TA, Laurora I, Chu H, Kafonek S. The lipid treatment assessment project (L-TAP). Archives of Internal Medicine 2000; 160: 459-67.

48 Pearson T, Kopin L. Bridging the treatment gap: improving compliance with lipid-modifying agents and Therapeutic Lifestyle Changes. Preventive Cardiology 2003; 6: 204-13.

49 Anderson JW. Diet first, then medication for hypercholesterolemia. Journal of the American Medical Association 2003; 290: $531-3$

50 Kedward J, Dakin L. A qualitative study of barriers to the use of statins and the implementation of coronary heart disease prevention in primary care. British Journal of General Practice 2003; 53: 684-9.

51 Honda K. Factors underlying variation in receipt of physician advice on diet and exercise: applications of the behavioral model of health care utilization. American Journal of Health Promotion 2004; 18: 370-7.

52 Gale Group. Physician advice and individual behaviors about cardiovascular disease risk reduction: seven states and Puerto Rico, 1997. Morbidity \& Mortality Weekly Report 1999; 48: $74-5$.

53 Nawaz H, Adams ML, Katz DL. Physician-patient interactions regarding diet, exercise, and smoking. Preventive Medicine 2000; 31: 652-7.

54 Yarzebski J, Bujor CF, Goldberg RJ, Spencer F, Lessard D, Gore JM. A community-wide survey of physician practices and attitudes toward cholesterol management in patients with recent acute myocardial infarction. Archives of Internal Medicine 2002; 162: 797-804.

55 Kushner RF. Barriers to providing nutrition counseling by physicians: a survey of primary care practitioners. Preventive Medicine 1995; 24: 546-52.

56 Sikand G, Kashyap ML, Wong ND, Hsu JC. Dietitian intervention improves lipid values and saves medication costs in men with combined hyperlipidemia and a history of niacin noncompliance. Journal of the American Dietetic Association 2000; 100: 218-24.

57 Dalgard C, Thuroe A, Haastrup B, Haghfelt T, Stender S. Saturated fat intake in patients with ischemic heart disease 1 year after comprehensive counseling but not after brief counseling. Journal of the American Dietetic Association 2001; 101: 1420-9.

58 Vale MJ, Jelinek MV, Best JD, Santamaria JD. Coaching patients with coronary heart disease to achieve the target cholesterol: a method to bridge the gap between evidencebased medicine and the 'real world' - randomized controlled trial. Journal of Clinical Epidemiology 2002; 55: 245-52.

59 The Vegetarian Resource Group. How Many Vegetarians are There? [online], 2004. Available at http://www.vrg.org/ journal/vj2003issue3/vj2003issue3poll.htm. Accessed 16 October 2005.

60 National Center for Health Statistics. Health, United States, 2004, With Chartbook on Trends in the Health of Americans Hyattsville, MD: National Center for Health Statistics, 2004. 